\title{
Correlations between the Respiratory Function and Cervical and Lumbar Range of Motion in Elderly People
}

\author{
Du-Jin Park, PT, PhD • Jun-Seok Kim, PT, PhD $•$ Young-In Hwang, PT, $\mathrm{PhD}^{2 \dagger}$
}

Department of Physical Therapy, College of Health Sciences, Catholic University of Pusan,

${ }^{1}$ Department of Physical Therapy, College of Biomedical Science, Kaya University, ${ }^{2}$ Department of Physical Therapy, College of Life and Health Sciences, Hoseo University

Received: June 4, 2021 / Revised: June 21, 2021 / Accepted: July 17, 2021

(c) 2021 J Korean Soc Phys Med

\section{| Abstract |}

PURPOSE: The respiratory function and range of joint mobility deteriorate due to aging, respectively, and the respiratory function may be related to the range of joint mobility. To the best of the authors' knowledge, there has been little research on how the deterioration of the range of joint mobility caused by aging is related directly to the respiratory function. This study investigated the relationship between the respiratory function and the range of joint motion in the cervical and lumbar regions of older adults.

METHODS: Thirty-two older adults participated in the study. The forced vital capacity (peak expiratory flow: PEF and forced expiratory volume in 1 second: FEV1) and the range of cervical joint motion were assessed in all subjects. The results were analyzed using the Pearson's correlation coefficient.

$\dagger$ Corresponding Author : Young-In Hwang young123@hoseo.edu, https://orcid.org/0000-0002-7314-1678 This is an Open Access article distributed under the terms of the Creative Commons Attribution Non-Commercial License (http://creativecommons.org/licenses/by-nc/3.0) which permits unrestricted non-commercial use, distribution, and reproduction in any medium, provided the original work is properly cited.
RESULTS: The respiratory function moderately correlated with age. A moderate correlation was observed between FEV1 and right cervical lateral flexion. PEF was moderately correlated with the lumbar lateral flexion. In addition, FEV1 correlated strongly with lumbar lateral flexion.

CONCLUSION: The respiratory function was correlated with the cervical and lumbar lateral flexion. Therefore, rehabilitation of the respiratory function should involve improving the limited range of motion of the joints, and a stretching program is needed for older adults.

Key Words: Elderly, Range of motion, Respiration

\section{Introduction}

The respiratory function in elderly adults decreases gradually as aging progresses. With age, increased ventilator demand is accompanied by increased oxygen cost during breathing, weakness of ventilator muscles, and dyspnea, which can be a significant constraint [1,2]. In addition, the potential consequences are accompanied by a decrease in muscle strength of the respiratory muscles and an increased resistance to ventilation, leading to a decrease in the peak respiratory forces and peak effort of 
ventilation, which can cause fatigue in continuous ventilator demand [2].

Another change in the elderly population is the decreased range of joint motion, which generally decreases both active and passive motion and decreases the active range of motion (ROM) more than passive motion [3]. In particular, the ROM of the neck joint decreased gradually from 30 years of age, and there was a significant decrease in extension and lateral flexion [4]. When comparing the cervical ROM between younger (20-30 years of age) and older people (79-90 years of age), the elderly group showed a significant decrease in flexion, extension, and lateral flexion of the neck [5]. In addition, limitations were observed in the older adults during movement of the hip joint, particularly the most restrictive ones with extension and lateral flexion3). Lumbar flexion, extension, and lateral flexion also decreased in elderly people [6].

The respiratory function should mainly involve the diaphragm. On the other hand, if there is respiratory depression, the muscles attached to the diaphragm will be used to force breathing using the large muscles, such as the rectus abdominis, obliques, and quadratus lumborum (QL) [7]. In particular, the unilateral QL muscle and the lumbar lateral flexor $[8,9]$ fixes the twelfth rib during movements of the thoracic cage during forced expiration $[10,11]$ and may be related to the peak expiratory flow (PEF), which is the maximal speed of expiration, or forced expiratory volume in one second (FEV1), which is the volume of air forced expiration in one second after maximal inspiration [12]. While the QL activates symmetrically, it retains the stability of the lower rib cage $[10,13]$. Thus, it may perform a better forced expiration function than the contraction of the unilateral QL.

As discussed above, the respiratory function and range of joint mobility deteriorated during aging, and the respiratory function may be related to the range of joint mobility. To the best of the authors' knowledge, there are no reports on how the deterioration of the range of joint mobility due to aging is related to the respiratory function. Some researchers showed that the cervical and lumbar mobility is limited in patients with chronic obstructive pulmonary disease (COPD) [14]. Therefore, it is necessary to examine the correlation between the cervical and lumbar mobility and respiration in the elderly.

Therefore, this study examined the relationship between the range of joint motion and respiratory function in older adults. The aims were to determine the respiratory function of the PEF and FEV1 and the correlation between respiratory function and cervical and lumbar ROM in older adults. The hypothesis of this study was that the decreased respiratory function of PEF and FEV1 correlated with the limitation of cervical and lumbar ROM in older adults.

\section{Methods}

\section{Subjects}

Thirty-two older adults participated in this study (men: 6, women: 26). The inclusion criteria were as follows: 1) age $>65$ years, 2) no cognitive impairment, 3) ability to walk indoors independently, and 4) ability to blow the mouthpiece independently in the assessment of respiratory function. The subjects were excluded if they could not walk indoors independently for at least three minutes and had neurological or musculoskeletal disorders that disturbed an independent gait. Study approval was obtained from the Hoseo University Institutional Review Board (1041231-190816-HR-097-02) and written informed consent was obtained from all participants.

\section{Measurement}

A Vitalograph PEF/FEV1Diary (Vitalograph Inc., Ennis, Ireland) was used to measure the PEF and FEV1 as indicators of pulmonary function in elderly subjects (Fig. 1). The reliability of the Vitalograph PEF/ FEV1 Diary was reported to be $77 \%$ [15], and the validity of FEV1 was $.97-.99[16,17]$. 


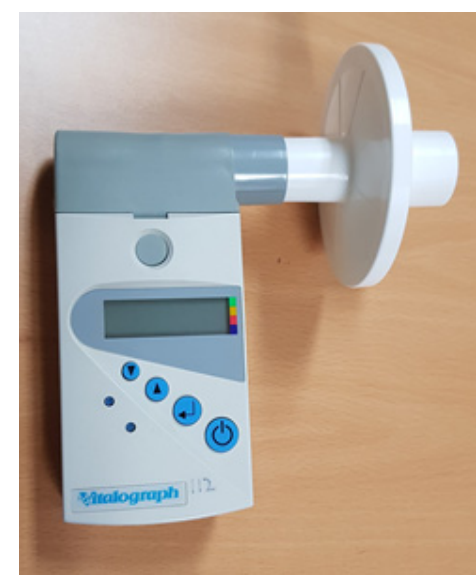

Fig. 1. Vitalograph to measure PEF and FEV1.

A dual digital inclinometer (ACUMARTM, Model ACU 360; Lafayette Instrument Company, Lafayette, IN, USA) was used to assess the cervical and lumbar mobility (Fig. 2). The intra-rater reliability of the digital inclinometer was $\geq .95$, and the validity between the goniometer and digital inclinometer was $\geq .85[18]$.

\section{Procedures}

All participants were seated comfortably on a chair for the PEF and FEV1 measurements three times. The investigators demonstrated to the participants how to bite the mouthpiece fully and breathe in and out. The participants were instructed to bite the mouthpiece fully, take a deep breath, breathe out as quickly and as hard as possible, and take a one-minute rest between trials. If a headache or dizziness occurred during the test, the investigators stopped immediately to rest for sufficient time and tried them again after recovery. The difference between the two highest FEV1 values obtained from the subjects was within $150 \mathrm{ml}$ to achieve reproducibility.

To measure the cervical ROM, the participants were instructed to sit on a chair with their hip and knee joints flexed to $90^{\circ}$. The participants maintained an upright posture in the sitting position as best as they possibly could so a physical therapist with more than 10 years of
Table 1. General Characteristics of the Subjects $(n=32)$

\begin{tabular}{cr}
\hline Characteristic & \multicolumn{1}{c}{ Mean \pm SD } \\
\hline Age (years) & $76.75 \pm 8.35$ \\
Height $(\mathrm{cm})$ & $151.05 \pm 6.68$ \\
Body weight $(\mathrm{kg})$ & $56.28 \pm 8.11$ \\
\hline
\end{tabular}

Values are means \pm standard deviation (SD)

experience could test the active ROM of neck flexion, extension, and lateral flexion on both sides. As it is simple for the investigators to prevent the subjects from moving their neck, the measurements of the range of motion of the neck were taken gently while sitting. Furthermore, the measurements of the cervical ROM, mainly in sitting position, using a dual inclinometer were used [19].

While the participants were in the upright standing position with their feet shoulder-width apart, the investigator measured the ROM of lumbar flexion, extension, and lateral flexion on both sides. The intra-trial reliability was high when using a dual inclinometer to measure the lumbar mobility in the standing position.

\section{Statistical Analysis}

The Pearson correlation coefficient was used to examine the correlations between the data of respiratory function and the ROM. The level of statistical significance (p) was set at .05. PASW Statistics version 20.0 (IBM Corp., Armonk, NY, USA) was used for all statistical analyses.

\section{Results}

Table 1 lists the characteristics of the 32 elderly participants. The mean values of the parameters assessed were as follows: lung capacity: PEF, $176.09 \pm 89.01 \mathrm{~L} / \mathrm{min}$, FEV1, $1.44 \pm .59 \mathrm{~L}$; neck ROM: flexion, $41.16 \pm 13.48^{\circ}$, extension, $41.28 \pm 15.75^{\circ}$, right lateral flexion, $28.03 \pm$ $8.79^{\circ}$, left lateral flexion, 26.66. $\pm 9.07^{\circ}$; and lumbar ROM: flexion, $19.16 \pm 5.87^{\circ}$, extension, $7.88 \pm 5.20^{\circ}$, right lateral flexion, $10.75 \pm 5.35^{\circ}$, left lateral flexion, $10.97 \pm 6.26^{\circ}$ 
(Table 2). Age was related to a negative PEF ( $r=-.392$, $\mathrm{p}<.05)$, FEV1 $(\mathrm{r}=-.535, \mathrm{p}<.01)$, cervical lateral flexion on both sides (right side: $\mathrm{r}=-.423, \mathrm{p}<.05$; left side: $-.448, \mathrm{p}<.05)$, and lumbar lateral flexion on both sides

Table 2. Average Respiratory Function, Neck and Lumbar Range of Motion

$(n=32)$

\begin{tabular}{cc}
\hline Parameters & Mean \pm SD \\
\hline PEF (L/min) & $176.09 \pm 89.01$ \\
FEV1 (L) & $1.44 \pm .59$ \\
Cervical Flexion $\left(^{\circ}\right)$ & $41.16 \pm 13.48$ \\
Cervical Extension $\left(^{\circ}\right)$ & $41.28 \pm 15.75$ \\
Cervical Right Lateral Flexion $\left(^{\circ}\right)$ & $28.03 \pm 8.79$ \\
Cervical Left Lateral Flexion $\left(^{\circ}\right)$ & $26.66 \pm 9.07$ \\
Lumbar Flexion $\left(^{\circ}\right)$ & $19.66 \pm 5.87$ \\
Lumbar Extension $\left({ }^{\circ}\right)$ & $7.88 \pm 5.20$ \\
Lumbar Right Lateral Flexion $\left(^{\circ}\right)$ & $10.75 \pm 5.35$ \\
Lumbar left Lateral Flexion $\left(^{\circ}\right)$ & $10.97 \pm 6.26$ \\
\hline
\end{tabular}

Values are means \pm standard deviation (SD)

FEV1: forced expiratory volume for 1 second, PEF: peak expiratory rate (right side: $\mathrm{r}=-.611, \mathrm{p}<.01$; left side: $\mathrm{r}=-.689, \mathrm{p}<$ $.01)$. PEF had a very strong correlation with FEV1 ( $\mathrm{r}=$ $.865, \mathrm{p}<.01)$. FEV1 showed a moderate correlation with the ROM of lumbar flexion $(r=.421, \mathrm{p}<.05)$. The right cervical lateral flexion showed a moderate correlation with FEV1 $(\mathrm{r}=.445, \mathrm{p}<.01)$. The ROM of lumbar lateral flexion showed a moderate correlation with PEF (right side: $\mathrm{r}=.512, \mathrm{p}<.01$; left side: $\mathrm{r}=.492, \mathrm{p}<.01)$. In addition, there was a moderate correlation between the lumbar lateral flexion and FEV1 (right side: $\mathrm{r}=.610, \mathrm{p}<.01$; left side: $r=.643, \mathrm{p}<.01)($ Table 3).

\section{Discussion}

These results show that a relationship exists between the factors of the respiratory function and the specific cervical and lumbar ROM. This study is unique because it examined the correlation between the respiratory function and joint mobility in elderly individuals.

With age, the respiratory function (PEF and FEV1), cervical and lumbar lateral flexion on both sides, and

Table 3. Correlation between the Respiratory Function and Neck and Lumbar Range of Motion

$(n=32)$

\begin{tabular}{|c|c|c|c|c|c|c|c|c|c|c|c|}
\hline & Age & PEF & FEV1 & $\mathrm{CF}$ & $\mathrm{CE}$ & RCLF & LCLF & $\mathrm{LF}$ & LE & RLLF & LLLF \\
\hline Age & 1 & & & & & & & & & & \\
\hline PEF & $-.392^{*}$ & 1 & & & & & & & & & \\
\hline FEV1 & $-.535^{* *}$ & $.865^{* *}$ & 1 & & & & & & & & \\
\hline $\mathrm{CF}$ & -.220 & .291 & .335 & 1 & & & & & & & \\
\hline $\mathrm{CE}$ & -.126 & -.040 & .013 & .187 & 1 & & & & & & \\
\hline RCLF & $-.423^{*}$ & .332 & $.445^{*}$ & $.469^{* *}$ & .040 & 1 & & & & & \\
\hline LCLF & $-.448^{*}$ & -.043 & .207 & $.392^{*}$ & $.463^{* *}$ & $.700^{* *}$ & 1 & & & & \\
\hline $\mathrm{LF}$ & $-.386^{*}$ & .281 & $.421^{*}$ & .132 & -.069 & .346 & .305 & 1 & & & \\
\hline LE & -.320 & .173 & .197 & -.167 & $.353^{*}$ & .068 & .197 & $.417^{*}$ & 1 & & \\
\hline RLLF & $-.611^{* *}$ & $.512^{* *}$ & $.610^{* *}$ & .132 & .035 & $.514^{* *}$ & $.469^{* *}$ & .328 & $.361^{*}$ & 1 & \\
\hline LLLF & $-.689^{* *}$ & $.492^{* *}$ & $.643^{* *}$ & .253 & -.063 & $.563^{* *}$ & $.439^{* *}$ & $.434^{*}$ & .183 & $.793^{* *}$ & 1 \\
\hline
\end{tabular}

Values are the means \pm standard deviation (SD)

CF: cervical flexion, CE: cervical extension, LCLF: left cervical lateral flexion, RCLF: right cervical lateral flexion, FEV1: forced expiratory volume for 1 second, LF: lumbar flexion, LE: lumbar extension, LLLF: left lumbar lateral flexion, RLLF: right lumbar lateral flexion, PEF: peak expiratory rate, ${ }^{*} \mathrm{p}<.05,{ }^{* *} \mathrm{p}<.01$ 


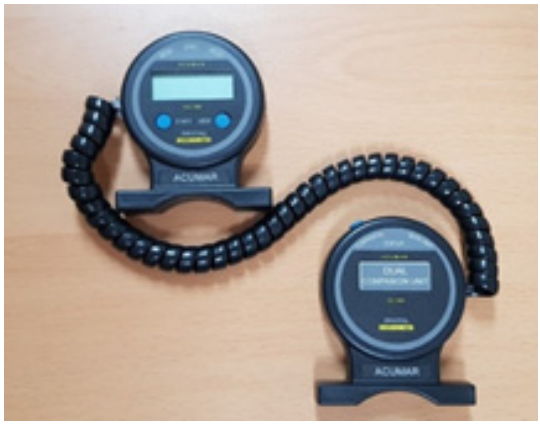

Fig. 2. Dual inclinometer to measure the cervical and lumbar range of motion.

lumbar flexion were negatively correlated. Previous studies revealed a consistent decrease of approximately $1 \%$ per year in various indicators of the breathing mechanism and dynamic lung function after 30 years of age [21,22]. The representative predictor related to age, FEV1, generally decreased after 20-25 years of age [23], and the decrease was accelerated in women older than 65 years of age $[24,25]$. In addition, age was negatively correlated with the maximal expiratory pressure of the respiratory system between the elderly and young groups [26]. The decrease in PEF and FEV1 during the forced expiratory effort could be related to the chest wall compliance, expiratory muscle strength, and narrow airways [27]. This decrease is involved in one of the structural factors that stiffen the chest wall to decrease the compliance of the upper rib cage due to a deterioration of the costal cartilages and dorsal spine [27].

Several studies suggest that the cervical ROM decreases with age [28-30]. In particular, Malmström et al. (2006) reported reduced cervical lateral flexion ROM compared to cervical flexion and extension as age increased [4]. Furthermore, in this study, aging was correlated with lumbar flexion and lumbar lateral flexion on both sides, which is consistent with previous studies indicating that the spinal mobility of the sagittal and coronal planes decreases with age $[6,31,32]$. Saidu et al. also suggested that the trunk flexion and right lateral flexion decreased in an 18-year interval, but the trunk extension showed the most significant decrease with advancing age [33]. On the other hand, there was no correlation with lumbar extension, which might be because the average age in this study was approximately 76 years, a relatively advanced age.

In this study, PEF was not correlated with the cervical ROM, and FEV1 was positively correlated with the right cervical lateral flexion. López-de-Uralde-Villanueva et al. reported that a cervical flexion strength of $45.6 \%$ in people with neck pain and a cervical lateral flexion strength of $53.9 \%$ in healthy people were predictors of the maximum expiration pressure [34].

The sternocleidomastoid muscle (SCM) also involves the accessory respiratory muscles, mainly activating as an inspiratory muscle [35]. When the function of the diaphragm and other respiratory muscles is decreased, the SCM compensates first, which is also activated during resting [36]. As muscles, such as the SCM and scalene, activate during cervical mobility and breathing, it could be inferred that the cervical motor dysfunction decreases the respiratory function [37]. The pressure pain threshold (PPT) is an indirect indication of stiffness and pain, and the PPT of the SCM is low in the elderly population [38]. This means that a low PPT value of the SCM shows a high potential for stiffness and pain of the SCM, which could affect the cervical lateral flexion and respiratory function. Therefore, it is necessary to utilize neck-stretching programs to strengthen the respiratory function of the elderly population.

The PEF and FEV1 were positively correlated with the lumbar flexion, particularly lumbar lateral flexion on both sides. Owing to the decrease in diaphragm function with age, the QL is one of the muscles also activated during forced expiration [39]. It originates in the traverse process of the L5 vertebra, iliac crest, and iliolumbar ligament and inserts into the transverse process of the L1-L5 vertebrae and inferior border of the twelfth rib. Its function is to depress the twelfth rib and flex the trunk laterally [40]. The lumbar part of the diaphragm is attached to the arcuate 
ligament and the L1-3 vertebrae with entangling fasciae of the QL [41]. Although small parts are involved, the subcostal muscle activated during expiration is also connected inferiorly with the QL in the terminal part. Hence, researchers suggested that the QL might be slightly effective in forced expiration [42].

The QL is divided into three layers (anterior, middle, and posterior) in view of anatomic structures [10]. According to Park et al., the posterior part of the QL showed increased muscular activation in the right lateral flexion during respiration [13], which was similar to the present study finding. Furthermore, the QL could help stabilize the vertebrae during respiration [9]. Hence, the QL may be used to compensate for the reduced diaphragm function during forced exhalation.

The right and left cervical lateral flexion showed a moderate correlation with cervical flexion and extension, which could be related to the SCM accompanied by cervical flexion and lateral flexion [43]. In addition, it could affect cervical extension considering the length-tension relationship of the SCM. Lumbar extension showed a moderate correlation with cervical extension and lumbar flexion, which was suggested to occur due to the relationship with the myofascial line connected between the neck and back extensors in the superficial back line [44]. Right and left lateral lumbar flexion showed moderate correlations with right and left lateral cervical flexion, as well as a strong correlation with the lumbar lateral flexion. Therefore, the SCM and external oblique muscle might be connected and affect the lateral line as the myofascial area [44]. The right lumbar lateral flexion showed a moderate correlation with lumbar extension. The left lumbar lateral flexion was moderately correlated with lumbar flexion, but these results are difficult to explain.

This study had several limitations. First, it used a small sample size and did not include a control group. Second, it is difficult to generalize the findings because the sex distribution of participants was tilted to female participants.
In addition, the respiration rate of males is higher than females [45] and the neck and trunk flexibility in males tends to be less than females [46]. In the future, it will be necessary to examine separate genders or a similar numbers of sexes. Third, the characteristics of the subjects, such as temporomandibular disease and dentures, were not investigated. The masseter is one of the muscles co-activated with the SCM [47], in which weakness is correlated with the cervical ROM [48]. Thus, it may be necessary for generalization that individuals with weakness of the masseter be excluded. Few studies have examined this correlation, so further studies will be needed in the future.

\section{Conclusion}

The respiratory function decreased with advancing age and was positively correlated with cervical and lumbar lateral flexion. Therefore, rehabilitation of the respiratory function for older adults could involve specifically checking the limited ROM of the joints and performing specific stretching programs.

\section{Acknowledgments}

This paper was supported by RESEARCH FUND offered from the Catholic University of Pusan (2020).

\section{References}

[1] Zaugg M, Lucchinetti E. Respiratory function in the elderly. Anesthesiol Clin North Am. 2000;18(1):47-58.

[2] Sharma G, Goodwin J. Effect of aging on respiratory system physiology and immunology. Clin Interv Aging. 2006;1(3):253-60.

[3] Guccione AA, Avers D, Wong R. Geriatric Physical Therapy (3rd ed.) St. Louis. Elsevier. 2011.

[4] Malmström EM, Karlberg M, Fransson PA, et al. Primary and coupled cervical movements: the effect of age, gender, 
and body mass index. A 3-dimensional movement analysis of a population without symptoms of neck disorders. Spine (Phila Pa 1976). 2006;31(2):E44-E50.

[5] Kuhlman KA. Cervical range of motion in the elderly. Arch Phys Med Rehabil. 1993;74(10):1071-9.

[6] Intolo P, Milosavljevic S, Baxter DG, et al. The effect of age on lumbar range of motion: A systematic review. Man Ther. 2009:14(6):596-604.

[7] Ludwig N, Gargano M, Formenti D, et al. Breathing training characterization by thermal imaging: a case study. Acta Bioeng Biomech. 2012;14(3):41-7.

[8] Andersson EA, Oddsson LI, Grundström H, et al. EMG activities of the quadratus lumborum and erector spinae muscles during flexion-relaxation and other motor tasks. Clin Biomech. 1996;11(7):392-400.

[9] McGill SM, Juker D, Kropf P. Quantitative intramuscular myoelectric activity of quadratus lumborum during a wide variety of tasks. Clin Biomech (Bristol, Avon). 1996;11(3): 170-2.

[10] Phillips S, Mercer S, Bogduk N. Anatomy and biomechanics of quadratus lumborum. Proc Inst Mech Eng H. 2008;222(2):151-9.

[11] De Permentier P. Quadratus lumborum: Anatomy, physiology and involvement in back pain. Journal of the Australian Traditional-Medicine Society. 2015;21(4): 241-2.

[12] Giannini D, Paggiaro PL, Cherson G, Bacci E, et al. Comparison between peak expiratory flow and forced expiratory volume in one second (FEV1) during bronchoconstriction induced by different stimuli. J Asthma. 1997;34(2):105-11.

[13] Park RJ, Tsao H, Cresswell AG, et al. Differential activity of regions of the psoas major and quadratus lumborum during submaximal isometric trunk efforts. J Orthop Res. 2012;30(2):311-8.

[14] Kazmi K, Hashmi GM, Ishaq H, Mehmood W. Effects of Chronic Obstructive Pulmonary Disease on Cervical and Lumbar spinal mobility. National Journal of Medical and Health Sciences (NJMHS). 2020, 2(1):31-7.
[15] Pelkonen, AS, Kikander K, Turpeinen M. Reproducibility of home spirometry in children with newly diagnosed asthma. Pediatr Pulmonol. 2000;29(1):34-8.

[16] Keskinen, H, Piirilä P, Nordman H, Nurminen M. Pocket-sized spirometer for monitoring bronchial challenge procedures. Clin Physiol. 1996;16(6):633-43.

[17] Tschopp JM, Roulin JP, Juilland A, et al. Evaluation of the reliability of 2 portable electronic spirometers. Schweiz Med Wochenschr. 1988;118(38):1382-5.

[18] Kolber MJ, Hanney WJ. The reliability and concurrent validity of shoulder mobility measurements using a digital inclinometer and goniometer: a technical report. Int J Sports Phys Ther. 2012;7(3):306-13.

[19] Wolfenberger VA, Bui Q., Batenchuk GB. A comparison of methods of evaluating cervical range of motion. J Manipulative Physiol Ther. 2002;25(3):154-60.

[20] MacDermid JC, Arumugam V, Vincent JI, Carroll KL. The reliability and validity of the computerized double inclinometer in measuring lumbar mobility. Open Orthop J. 2014;8:355-60.

[21] Janssens JP, Pache JC, Nicod LP. Physiological changes in respiratory function associated with ageing. Eur Respir J. 1999;13(1):197-205.

[22] Fletcher C, Peto R. The natural history of chronic airflow obstruction. Br Med J. 1977;1(6077):1645-8.

[23] Hankinson JL, Odencrantz JR, Fedan KB. Spirometric reference values from a sample of the general U.S. population. Am J Respir Crit Care Med. 1999;159(1): 179-87.

[24] Fowler RW, Pluck RA, Hetzel MR. Maximal expiratory flow-volume curves in Londoners aged 60 years and over. Thorax. 1987;42(3):173-82.

[25] Knudson RJ, Lebowitz MD, Holberg CJ, et al. Changes in the normal maximal expiratory flow-volume curve with growth and aging. Am Rev Respir Dis. 1983; 127(6):725-34.

[26] Bunki H, Shibata N, Yorimoto A. Functional characteristics and measurement significance of respiratory muscle 
strength in the elderly. Health Evaluation \& Promotion. 2013;40(4):451-6.

[27] Lalley PM. The aging respiratory system--pulmonary structure, function and neural control. Respir Physiol Neurobiol. 2013;187(3):199-210.

[28] Chen J, Solinger AB, Poncet JF, et al. Meta-analysis of normative cervical motion. Spine. 1999;24(5):1571-8.

[29] Feipel V, Rondelet B, Le Pallec J, et al. Normal global motion of the cervical spine: an electrogoniometric study. Clin Biomech (Bristol, Avon). 1999;14(7):462-70.

[30] Walmsley RP, Kimber P, Culham E. The effect of initial head position on active cervical axial rotation range of motion in two age populations. Spine (Phila Pa 1976). 1996;21(21):2435-42.

[31] Einkauf DK, Gohdes ML, Jensen GM, et al. Changes in spinal mobility with increasing age in women. Phys Ther. 1987;67(3):370-5.

[32] Mayer TG, Tencer AF, Kristoferson S, Mooney V. Use of noninvasive techniques for quantification of spinal range of motion in normal subjects and chronic low-back dysfunction patients. Spine (Phila Pa 1976). 1984;9(6): 588-95.

[33] Saidu IA, Maduagwu SM, Abbas AD, et al. Lumbar spinal mobility changes among adults with advancing age. J Midlife Health. 2011;2(2):65-71.

[34] López-de-Uralde-Villanueva I, Sollano-Vallez E, Del Corral T. Reduction of cervical and respiratory muscle strength in patients with chronic nonspecific neck pain and having moderate to severe disability. Disabil Rehabil. 2018;40(21):2495-504.

[35] Campbell EJM. The role of the scalene and sternomastoid muscles in breathing in normal subjects; an electromyographic study. J Anat. 1955;89(Pt 3):378-86.

[36] Lyall RA, Donaldson N, Polkey MI, et al. Respiratory muscle strength and ventilatory failure in amyotrophic lateral sclerosis. Brain. 2001;124(Pt 10):2000-13.

[37] Legrand A, Schneider E, Gevenois PA, et al. Respiratory effects of the scalene and sternomastoid muscles in humans. J Appl Physiol. 2003;94(4):1467-72.

[38] De Rui M, Marini I, Bartolucci ML, et al. Pressure pain threshold of the cervico-facial muscles in healthy elderly people: the role of gender, age and dominance. Gerodontology. 2015;32(4):274-80.

[39] Oatis CA. Mechanics and pathomechanics of the muscle of the thoracic spine, kinesiology: The mechanics and pathomechanics of human movement. Philadelphia. PA: Lippincott Williams \& Wilkins. 2004.

[40] Neumann DA. Kinesiology of the musculoskeletal system: Foundations for rehabilitation. 2nd ed. St. Louis. Elsevier. 2010.

[41] Wallden M. The diaphragm - More than an inspired design. J Bodyw Move Ther. 2017;21(2):342-9.

[42] Bordoni B, Varacallo M. Anatomy, Abdomen and Pelvis, Quadratus Lumborum. Treasure Island. StatPearls Publishing. 2021.

[43] Kim MS. Neck kinematics and sternocleidomastoid muscle activation during neck rotation in subjects with forward head posture. J Phys Ther Sci. 2015;27(11): 3425-28.

[44] Myers TW. Anatomy trains: Myofacial Meridians for Manual and Movement Therapists. 3rd Edi. Edinburgh, Churchill Livingstone. 2014.

[45] Holguera RM, Nievesa AIT, Torresa RR, et al. The effects of truncal adiposity in forced spirometery: sex differences. Respir Physiol Neurobiol. 2018:247:167-73.

[46] Hwang J, Jung MC. Age and sex differences in ranges of motion and motion patterns. Occup Ergon. 2015; 21(2):173-186.

[47] Palazzi C, Miralles R, Soto MA, Santander H, Zuñiga C, et al. Body position effects on EMG activity of sternocleidomastoid and masseter muscles in patients with myogenic cranio-cervical-mandibular dysfunction. Cranio. 1996;14(3):200-9.

[48] Ballenberger N, von Piekartz H, Paris-Alemany A, et al. Influence of different upper cervical positions on electromyography activity of the masticatory muscles. J Manipulative Physiol Ther. 2012;35(4):308-18. 